\title{
Formulation and Evaluation of Topical Proniosomal Gel of Ciclopirox for Antifungal Therapy
}

\author{
Suvarnalata Suhas Mahajan*, RY Chaudhari, VR Patil \\ Department of Pharmaceutics, TVES's Hon. Loksevak Madhukarrao Chaudhari, College of Pharmacy, Faizpur, Jalgaon, Maharashtra, INDIA.
}

\begin{abstract}
Objectives: The objective of existent effort was topical proniosomal gel formulation and evaluation from the proniosomes of Ciclopirox to improve poor skin penetration and residence of the topical antifungal drugs. Methods: The co-acervation phase separation method was used to prepare proniosomes by using combination of different grades of non-ionic surfactant, cholestrol and lecithin. Characterized for $\mathrm{pH}$, encapsulation efficiency, Particle size, in vitro drug permeation. Selected batches were converted into topical proniosomal gel and evaluated for ex vivo permeation. Then best fitted formulation batch C5CF8 were differentiate with marketed preparation for ex vivo drug release and anti-fungal activity. Results: Proniosomal gel $\mathrm{pH}$ be there $5.61 \pm 0.25$ to $7.31 \pm 0.06$ and encapsulation efficiency 82.40 to $92.20 \%$ and particle size $3.20 \pm 0.15$ to $6.45 \pm 0.20$. In vitro drug release is in between 37.65 to $57.04 \%$. Among the formulations CF1, CF2, CF3, CF4 and CF5 were developed into carbopol topical gel as C1CF2, C2CF32, C3CF5, C4CF6 and C5CF8 and evaluated for ex vivo drug permeation. Among these optimized formulation C5CF8 showed drug permeation $59.39 \pm 0.10 \%$ at $12 \mathrm{hr}$. with a flux value of $5.24 \mu \mathrm{g} /$
\end{abstract}

$\mathrm{cm}^{2} / \mathrm{hr}$., permeability coefficient of $0.262 \mathrm{~cm}^{2} / \mathrm{hr}$. and higher correlation coefficient $\mathrm{R}^{2} 0.9949$ for zero order drug release and hence follows zero order release kinetics. The C5F8 showed prolonged drug release and zone of inhibition value higher for carbopol gel as compared to marketed preparation Conclusion: Developed carbopol topical gel had potential to act as controlled release drug carrier which prolonged the drug release for number of hours.

Key words: Non-ionic surfactant, Permeation, Entrapment efficiency, Gel, Topical, in vitro antifungal.

\section{Correspondence}

Prof. Suvarnalata S. Mahajan

College of Pharmacy, TVES's Hon. Loksevak Madhukarrao Chaudhari, Faizpur, Jalgaon, Maharashtra, INDIA.

Phone no: +91 9970245576

Email: suvarnalatampharm@gmail.com

DOI: 10.5530/ijpi.2021.1.11

\section{INTRODUCTION}

Ciclopirox, a broad-spectrum antifungal, is hydroxypyridone derivative that has mechanism of action unlike from other marketed antifungal agents like the azoles and therefore the allylamines. It has a wide range of action against dermatophytes, yeasts, filamentous fungi and bacteria. It has a biological half-life of $1.7 \mathrm{hr}$ and bioavailability of $<5 \%$ with prolonged use. ${ }^{1}$ Ciclopirox does not affect sterol synthesis. Ciclopirox inhibits cellular uptake of essential compounds and at high concentrations can alter cell permeability. ${ }^{2}$

Proniosomes are vesicular systems, during which the vesicles are made from non-ionic based surfactants, cholesterol and other additives These semisolid liquid gel means proniosomes get arranged by liquefying the surfactant during small quantity of an appropriate solvent explicitly ethanol and this upon hydration with bit of water to get a gel. These liquid crystal-like compact niosomes crossbreeds which will be transformed into niosomes upon hydration or intrinsically are often utilized in transdermal /topical applications. Proniosomal gel is usually present during a transparent, luminous, or white semisolid gel consistency, which was physically stable during storage and transport. ${ }^{3}$ The surfactant molecule direct themselves such the hydrophilic ends of the non-ionic surfactant face outer, whereas the hydrophobic ends are within the opposed direction to make the bilayer. ${ }^{4}$

Proniosomes are dehydrated formulations of surfactant-covered carrier, which will be taken out as required and rehydrated by shortterm agitation in warm water. Reduced the problems associated with niosomes like physical stability, clump formation, fusion and dripping. Proniosomes providing accessibility in delivery, transport, storage and dosing. Dehydrated proniosomes stability is more than a premanufactured niosomal formulation. Proniosomes are equivalent to conventional niosomes in respect to release studies. This Proniosomal drug delivery have fascinated towards transdermal drug delivery since surfactants perform the role of penetration enhancers as well as they can entangle both hydrophilic and lipophilic drugs. ${ }^{5}$ Both phospholipids and non-ionic surfactants act as penetration enhancers. Non-ionic surfactant and cholesterol ratio could effect on entrapment efficiency and on release characteristics of the incorporated drugs. ${ }^{6}$

The purpose of present study to formulate proniosomes as transporters for topical delivery of Ciclopirox. Proniosomes converts into niosomes upon hydration which can prove as substitute to increase poor skin penetration and residence time of the topical antifungal drugs. ${ }^{7}$

\section{MATERIALS AND METHODS}

\section{Materials}

Soya lecithin, cholesterol, carbopol 934, Non-ionic surfactants span 20,40,60,80 were purchased from Himedia Laboratories Pvt. Ltd., Mumbai. Ciclopirox drug purchased from Swapnroop Drugs and Pharmaceuticals, Aurangabad. Ethanol and other reagents and solvents were purchased from Research Lab. Fine Chem Industries, Mumbai. Dialysis membrane (Himedia Laboratories Pvt. Ltd., Av. flat width: 32.34 $\mathrm{mm}$; Av. diameter: $21.5 \mathrm{~mm}$ )

\section{Methods}

\section{Drug -excipients compatibility study by FTIR spectroscopy}

Drug-excipient interaction was studied by FTIR spectroscopy. The FTIR spectrum were noted for pure Ciclopirox and with different excipient 
mixture individually using FTIR Spectrophotometer (Model-FTIR 8400 S, Shimadzu, Japan). The scanning range was $400-4000 \mathrm{~cm}^{-1}$ and the resolution of $1 \mathrm{~cm}^{-1}$. $^{2}$

\section{Method of preparation of Proniosomal gel of Ciclopirox}

Ciclopirox proniosomes were prepared by co-acervation phase separation method reported by Vora et al. A clean glass vial was taken in that drug, surfactant, lecithin and cholesterol were added and mixed it. A measured amount of ethanol was added to glass vial to dissolve all the ingredients. The glass vial was enclosed with a closure to avoid the solvent loss. All the vials are then taken into a water bath, warmed at $60-$ $70^{\circ} \mathrm{C}$ for nearly $5 \mathrm{~min}$, till the surfactants were dissolved completely. In that PBS was added and warmed on a water bath till clear solution was formed. The glass vials was set aside in a dark place for allowed to cool at room temperature till the dispersion was converted to proniosomal gel. Composition of proniosomal gel formulations were given in Table $1 .{ }^{8,9}$

\section{Characterization of Proniosomal Gel of Ciclopirox Physical appearance of proniosomal gel}

Proniosomal gel was also observed by optical microscope at 10X and 40 $\mathrm{X}$ magnification to note crystal characteristics of gel. The appearance of each formulations was checked for its colour, consistency and fluidity by spreading a thin layer of gel on a glass slide and placing the cover slip on it. ${ }^{10}$

\section{$\mathrm{PH}$ determination}

In $25 \mathrm{ml}$ of distilled water $1 \mathrm{gm}$ of gel was dissolved and the electrode was immersed in to gel formulation for 30 min till constant reading was achieved. ${ }^{10}$

\section{Vesicle size determination}

After hydration, the aqueous dispersion of niosomes was observed under optical microscope at $10 \mathrm{X}$ and $40 \mathrm{X}$ magnification. The particle sizes of vesicles were measured using a calibrated ocular and stage micrometer built-in optical microscope. ${ }^{10}$

\section{Entrapment efficiency determination}

In a glass tube $0.2 \mathrm{gm}$ of proniosomal gel was taken and $10 \mathrm{ml}$ of PBS $\mathrm{PH} 7.4$ containing $10 \% \mathrm{v} / \mathrm{v}$ methanol was added. This aqueous suspension was sonicated by using sonicator bath for $10 \mathrm{~min}$ followed by centrifugation at $18000 \mathrm{rpm}$ at $5^{\circ} \mathrm{C}$ for $40 \mathrm{~min}$. The supernatant was collected and assayed by UV method. The percentage of drug encapsulation $(\mathrm{EE}(\%))$ was calculated by, ${ }^{11}$

$\mathrm{EE} \%=\mathrm{C}_{\mathrm{t}}-\mathrm{C}_{\mathrm{f}} / \mathrm{Ct} \times 100$

Where, $C_{t}=$ total concentration of drug, $C_{f}=$ Concentration of free drug

\section{Differential Scanning Colorimetry (DSC) studies}

The differential calorimetric scanning analysis of Ciclopirox and Ciclopirox loaded proniosomal gel sample was carried out by using DSC 1 Mettler Toledo. The drug sample and Ciclopirox loaded proniosomal gel sample were closed in aluminium pan and the DSC thermograms were recorded at a heating rate of $10^{\circ} \mathrm{C} / \mathrm{min}$ in the range of 30 to $300^{\circ} \mathrm{C}$ under constant purging of nitrogen at $50 \mathrm{ml} / \mathrm{min}$. An empty closed pan was used as reference. DSC graphs for Ciclopirox and its formulation were recorded as shown in Figure 1 (a) and (b) respectively. ${ }^{12,13}$

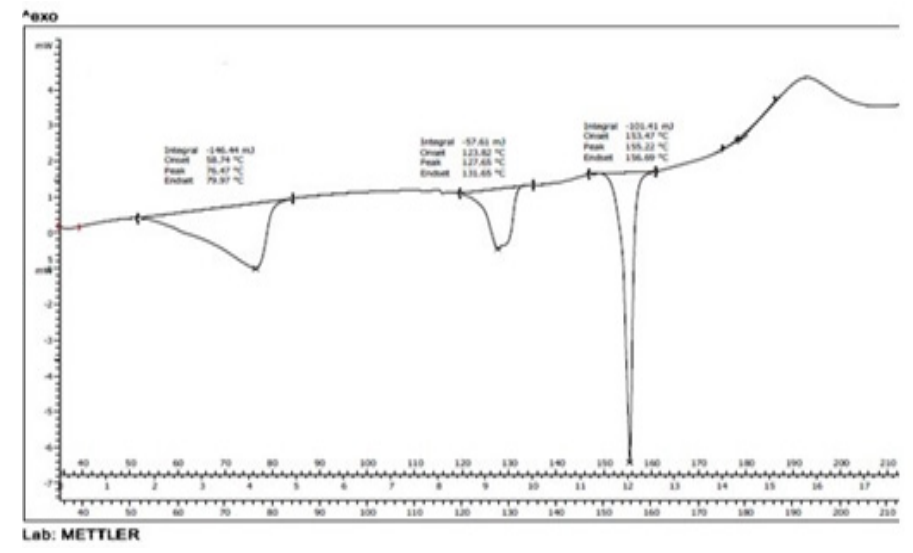

Figure 1: (a) Differential Scanning colorimetry (DSC) thermogram of Ciclopirox.

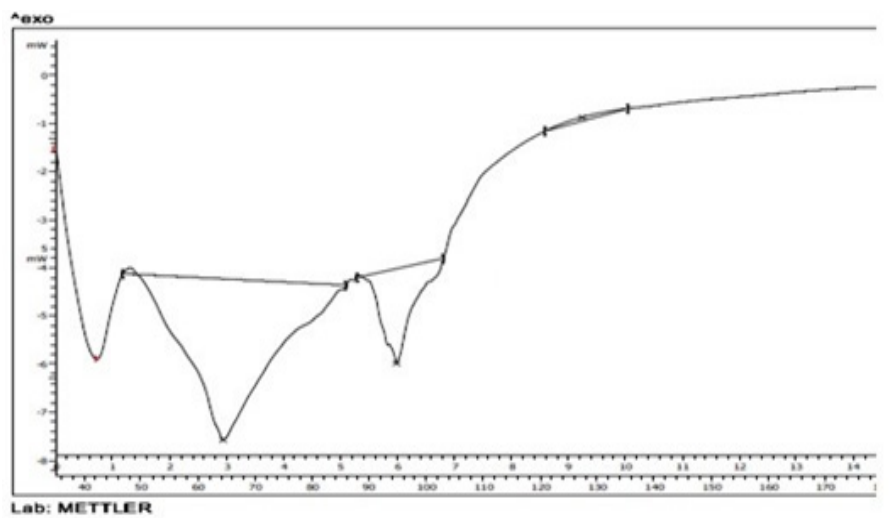

Figure 1: (b) Differential Scanning colorimetry (DSC) thermogram of Proniosomal gel formulation of Ciclopirox.

Table 1: Composition of proniosomal gel formulations of Ciclopirox.

\begin{tabular}{|c|c|c|c|c|c|c|c|c|c|c|}
\hline Formulation Code & CF1 & $\mathrm{CF} 2$ & CF3 & CF4 & CF5 & CF6 & CF7 & CF8 & CF9 & CF10 \\
\hline Ciclopirox(mg) & 40 & 40 & 40 & 40 & 40 & 40 & 40 & 40 & 40 & 40 \\
\hline Span20(mg) & 1800 & & & & 900 & 900 & 900 & & & \\
\hline Span $40(\mathrm{mg})$ & & 1800 & & & 900 & & & 900 & 900 & \\
\hline Span60(mg) & & & 1800 & & & 900 & & 900 & & 900 \\
\hline Span $80(\mathrm{mg})$ & & & & 1800 & & & 900 & & 900 & 900 \\
\hline Cholestrol(mg) & 200 & 200 & 200 & 200 & 200 & 200 & 200 & 200 & 200 & 200 \\
\hline Lecithin(mg) & 1800 & 1800 & 1800 & 1800 & 1800 & 1800 & 1800 & 1800 & 1800 & 1800 \\
\hline Ethanol(ml) & 1.0 & 1.0 & 1.0 & 1.0 & 1.0 & 1.0 & 1.0 & 1.0 & 1.0 & 1.0 \\
\hline $\begin{array}{l}\text { Phosphate buffer PH } 7.4 \\
(\mathrm{ml})\end{array}$ & 1.0 & 1.0 & 1.0 & 1.0 & 1.0 & 1.0 & 1.0 & 1.0 & 1.0 & 1.0 \\
\hline
\end{tabular}




\section{The in vitro drug release studies}

The in vitro drug release studies of the Ciclopirox proniosomal gel formulations were carried out in Franz Diffusion cell using Dialysis. The volume of receptor compartment was $15 \mathrm{ml}$. The area of donor compartment exposed to receptor compartment was $3.14 \mathrm{~cm}^{2}$. Before experiment the membrane was soaked in PBS pH 7.4 containing 10\%v/v methanol for overnight. The membrane was mounted between the donor and receptor compartment which were seized together with a clamp. The receiver compartment contained PBS pH 7.4 containing 10\% $\mathrm{v} / \mathrm{v}$ methanol and in the upper donor compartment a weighed amount of proniosomal gel equivalent to $10 \mathrm{mg}$ of drug was spread uniformly on the membrane. The receptor phase PBS pH 7.4 containing $10 \% \mathrm{v} / \mathrm{v}$ methanol was constantly stirred with help of magnetic stirrer and was surrounded by a water jacket maintained at temperature of $37 \pm 0.5^{\circ} \mathrm{C}$ during the experiments. $1 \mathrm{ml}$ of sample was taken out at time intervals of $1,2,3,4,5,6,7,8,9,10,11,12 \mathrm{hr}$ and the fresh buffer solution of same amount was added to maintain the sink condition in the receiver compartment, analyzed spectrophotometrically at $305 \mathrm{~nm}$. By determining the amount of Ciclopirox released at various time intervals, the Cumulative \% drug release versus time was plotted. ${ }^{8}$

\section{Surface Morphology by SEM}

For scanning electron microscopy take $0.2 \mathrm{gm}$. of Ciclopirox proniosomal gel in a glass tube was diluted with $10 \mathrm{ml}$ of $\mathrm{pH} 7.4$ PBS. Vesicles were examined using Model No. S-4800 Type-II, Hitachi, Japan. ${ }^{14}$

\section{Formulation of carbopol topical proniosomal gel:}

Based upon entrapment efficiency and in vitro drug release proniosomal gel formulation $\mathrm{CF} 2, \mathrm{CF} 3, \mathrm{CF} 5, \mathrm{CF} 6$ and $\mathrm{CF} 8$ were selected for ex vivo permeation studies. Further topical applicability of the selected formulation was enhanced by the development of gel formulation using carbopol 934.1.0 g of carbopol 934 powder was dispersed into distilled water which was strongly stirred by magnetic stirrer, allowed to hydrate for $24 \mathrm{hr}$. In that methyl paraben was mixed well. Triethanolamine was added into dispersion to neutralized and adjust the $\mathrm{pH} 7.4$ by using $\mathrm{pH}$ meter. Appropriate amount of Ciclopirox proniosomal gel were then incorporated into gel-base with continuous stirring until homogenous formulation was attained.

\section{EVALUATION OF CARBOPOL PRONIOSOMAL GEL}

Carbopol gel were evaluated for Physical examination, $\mathrm{PH}$, Viscosity determination, Drug content, Spreadability, Extrudability study. The results are Table 2 .

\section{Ex vivo permeation through wistar rat skin}

Exvivo skin permeation studies were performed with Institutional Animal Ethical Committee approval and the number were IAEC/01-P1/2017-18. Hairless wistar rat abdominal skin was used. Prepared skin was enveloped in aluminium foil and put in storage in a freezer at $-20^{\circ} \mathrm{C}$ till further use. The skin was defrosted at temperature when required. ${ }^{15}$ The rat skin was attached among the donor and receptor compartment with the stratum corneum facing upper side on the diffusion cell. To maintain sink conditions PBS pH 7.4 containing $10 \%$ v/v methanol was taken in receptor compartment. Maintained the temperature at $37 \pm 0.5^{\circ} \mathrm{C}$. Carbopol gel formulation equivalent to $20 \mathrm{mg}$ of Ciclopirox was spread over the rat skin. The receptor compartment content was stirred with the help of magnetic beads. The sample was taken out at time intervals of $1,2,3,4,5,6,7,8,9,10,11,12 \mathrm{hr}$ and the fresh buffer solution of same amount was added in the receiver compartment. The samples were analyzed spectrophotometrically at $305 \mathrm{~nm}$. The cumulative quantity of drug permeated $(\mathrm{Q})$ at different time intervals and various parameters like permeability coefficient (Kp), enhancement ratio (ER) and steady state flux (Jss), were calculated using following equations, ${ }^{12}$ Steady state flux $\left(\mathrm{J}_{\mathrm{ss}}\right)=$ Quantity of drug permeated / (time $\times$ area of membrane)

$$
\mathrm{Q} /(\mathrm{t} \times \mathrm{A})
$$

Permeability Coefficient $\left(\mathrm{K}_{\mathrm{p}}\right)=$ flux /initial concentration of drug in donor chamber

$=\mathrm{J}_{\mathrm{ss}} / \mathrm{D}_{0}$

Enhancement Ratio (ER) = Jss of proniosomes/Jss of control

\section{Stability studies}

The stability study was performed by following the ICH guidelines. The carbopol gel formulations C5CF8 was filled in tightly closed glass vial and subjected to stability testing. The formulations were preserved at refrigerated environment that is $4 \pm 1^{\circ} \mathrm{C}$ and at room temperature that is $25 \pm 2^{\circ} \mathrm{C}$ and after 3 months formulations were analyzed for vesicle size and entrapment efficiency. ${ }^{16}$

\section{In vitro antifungal study}

In a $500 \mathrm{ml}$ of conical flask required amount of saboured dextrose agar was taken and $250 \mathrm{ml}$ of purified water is added. Heat is applied to dissolve the saboured dextrose agar completely. Sterilized for $15 \mathrm{~min}$ at $121^{\circ} \mathrm{C}$ at $15 \mathrm{lb}$ pressure in autoclave for about $20 \mathrm{~min}$. Then cooled it at room temperature and the fungal strain (Candida albicans) was dispersed in the medium and then the medium was poured it in to the required petridish and allowed it cool it until it get solidified at room temperature and then the cups are bored in agar plate by using cork borer having $6 \mathrm{~mm}$ diameter and calculated concentration of the gel formulation (C5CF8) and Marketed preparations were placed in the bores ${ }^{17}$ and incubated the petri plates for $72 \mathrm{~h}$ at $28^{\circ} \mathrm{C}$ in incubators. ${ }^{18}$ As shown in Figure 2 the zone of inhibition was measured and calculated the radius of the zone of inhibition.

\section{RESULTS}

The FTIR spectrum graph of drug Ciclopirox Figure 3(a) have observed characteristic peaks at 2922.16, 2852.72/cm for C-H stretch, 1535.34/ $\mathrm{cm}$ for $\mathrm{C}=\mathrm{C}$ stretch, $1637.56 / \mathrm{cm}$ for $\mathrm{C}==\mathrm{O}$ stretch, $1444.68 / \mathrm{cm}$ for $\mathrm{C}-\mathrm{C}$ stretch. Ciclopirox with cholestrol (b) observed peaks at $2926.01 / \mathrm{cm}$ for $\mathrm{C}-\mathrm{H}$ stretch, $1562.34 / \mathrm{cm}$ for $\mathrm{C}=\mathrm{C}$ stretch, $1635.34 / \mathrm{cm}$ for $\mathrm{C}==\mathrm{O}$ stretch, $1444.68 / \mathrm{cm}$ for C-C stretch

Table 2: Characterization of proniosomal gel formulations for $\mathrm{pH}$, Vesicle size and Encapsulation Efficiency.

\begin{tabular}{cccc}
\hline $\begin{array}{c}\text { Formulation } \\
\text { code }\end{array}$ & $\mathrm{pH}^{*}$ & $\begin{array}{c}\text { Mean Vesicle size } \\
(\mu \mathrm{m})^{*}\end{array}$ & $\begin{array}{c}\text { Encapsulation } \\
\text { efficiency }\end{array}$ \\
\hline CF1 & $6.41 \pm 0.17$ & $6.45 \pm 0.20$ & 83.15 \\
CF2 & $7.22 \pm 0.20$ & $5.80 \pm 0.25$ & 87 \\
CF3 & $6.91 \pm 0.15$ & $3.20 \pm 0.15$ & 88.25 \\
CF4 & $6.70 \pm 0.24$ & $4.65 \pm 0.36$ & 82.40 \\
CF5 & $7.14 \pm 0.10$ & $4.10 \pm 0.16$ & 87.10 \\
CF6 & $5.61 \pm 0.25$ & $3.50 \pm 0.35$ & 90.15 \\
CF7 & $6.14 \pm 0.12$ & $3.70 \pm 0.42$ & 83.23 \\
CF8 & $6.92 \pm 0.21$ & $4.25 . \pm 0.12$ & 92.20 \\
CF9 & $7.31 \pm 0.06$ & $5.10 \pm 0.30$ & 85.50 \\
CF10 & $6.29 \pm 0.08$ & $6.42 \pm 0.33$ & 86.17 \\
\hline
\end{tabular}




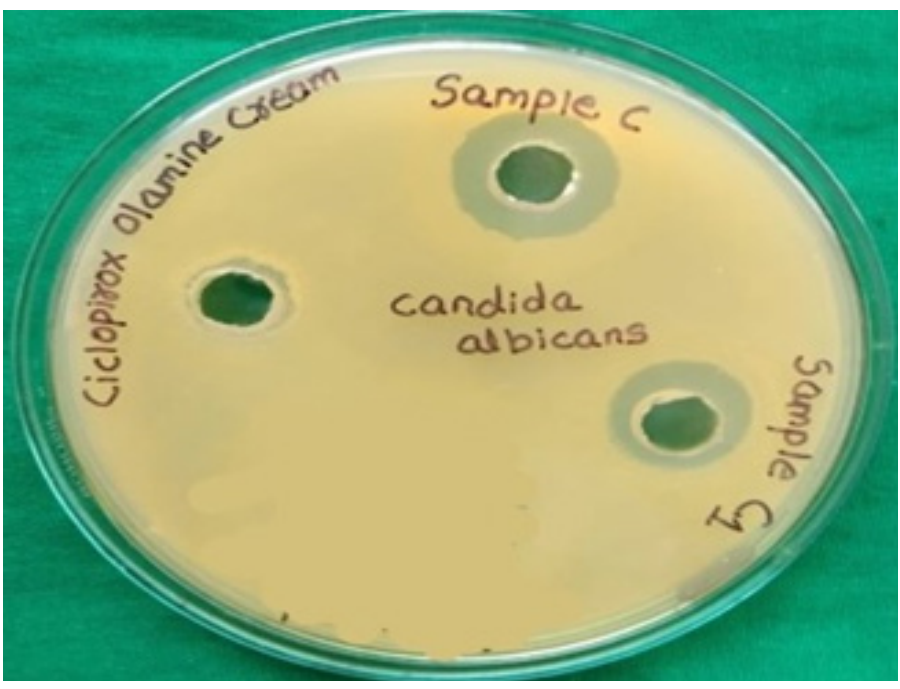

Figure 2: Zone of inhibition of Ciclopirox marketed preparations and Carbopol gel.

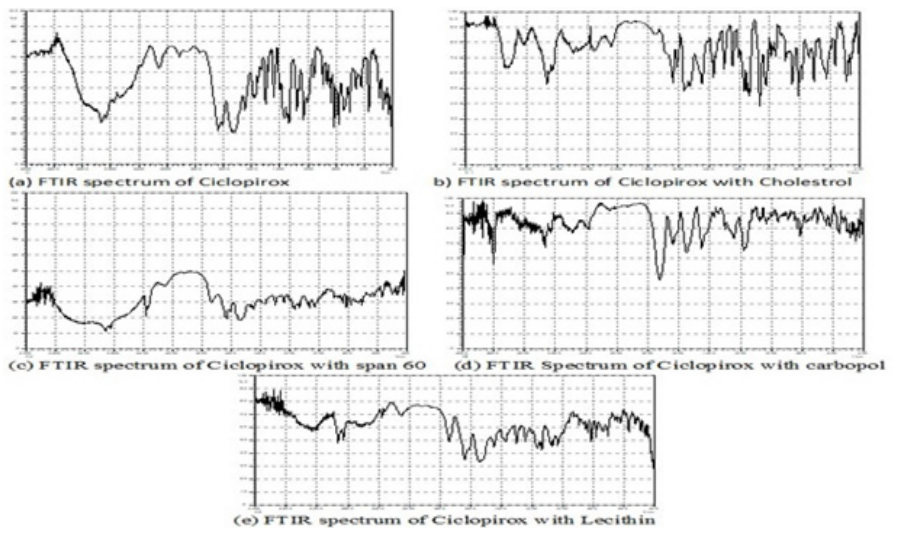

Figure 3: FTIR spectrum.

Ciclopirox with span 60 (c) observed peaks at 2922.16,2845/cm for C-H stretch, $1541.12 / \mathrm{cm}$ for $\mathrm{C}=\mathrm{C}$ stretch, $1631.78 / \mathrm{cm}$ for $\mathrm{C}==\mathrm{O}$ stretch, $1444.68 / \mathrm{cm}$ for C-C stretch. Ciclopirox with carbopol (d) observed peaks at $2924.09 / \mathrm{cm}$ for $\mathrm{C}-\mathrm{H}$ stretch, $1546.91 / \mathrm{cm}$ for $\mathrm{C}=\mathrm{C}$ stretch, $1629.85 / \mathrm{cm}$ for $\mathrm{C}==\mathrm{O}$ stretch, $1450.47 / \mathrm{cm}$ for C-C stretch. Ciclopirox with lecithin (e) observed peaks at $2931.8,2852.72 / \mathrm{cm}$ for $\mathrm{C}-\mathrm{H}$ stretch, $1535.34 / \mathrm{cm}$ for $\mathrm{C}=\mathrm{C}$ stretch, $1631.78 / \mathrm{cm}$ for $\mathrm{C}==\mathrm{O}$ stretch, $1444.68 /$ $\mathrm{cm}$ for $\mathrm{C}-\mathrm{C}$ stretch were shown in Figure 3. (a), (b), (c), (d) and (e) respectively. Ciclopirox and physical mixture of all the ingredients also shows similar peaks of Ciclopirox. All these peaks were not affected and prominently observed in FTIR spectrum of Ciclopirox along with polymers. There was no known chemical interaction observed among the drug and excipients.

Proniosomal gel of Ciclopirox prepared by using Span $(20,40,60)$ have pale yellow semi solid gel like appearance and span 80 have light brownish gel like appearance. Mean vesicle size of Ciclopirox was presented in Table 2. The optical microscopic images of hydrated CF5, CF6 and CF8 proniosomal gel formulations were presented in Figure 4 (a), (b) and (c) respectively. The photomicrograph shown that the niosomes are spherical in shape with no bunch formation was observed. The DSC analysis of Ciclopirox showed a large endothermic peak at $155.22^{\circ} \mathrm{C}$ which denotes the melting point of Ciclopirox. This prominent peak was not observed in the DSC thermogram of formulation CF8.
Table 3: Release kinetics of formulation from in vitro drug release.

\begin{tabular}{ccccc}
\hline $\begin{array}{c}\text { Formulation } \\
\text { code }\end{array}$ & \multicolumn{4}{c}{ Correlation coefficient of model fitting $\left(R^{2}\right)$} \\
\hline & Zero order & First order & Higuchi & Peppa's \\
\hline CF1 & 0.9827 & 0.9881 & 0.9768 & 0.9848 \\
CF2 & 0.9918 & 0.9958 & 0.9876 & 0.9969 \\
CF3 & 0.9906 & 0.9937 & 0.9877 & 0.9928 \\
CF4 & 0.9774 & 0.9836 & 0.9757 & 0.9838 \\
CF5 & 0.9936 & 0.9896 & 0.9734 & 0.9812 \\
CF6 & 0.9851 & 0.993 & 0.9864 & 0.9885 \\
CF7 & 0.9889 & 0.9961 & 0.9878 & 0.9639 \\
CF8 & 0.9936 & 0.9933 & 0.9821 & 0.9951 \\
CF9 & 0.9834 & 0.9918 & 0.9874 & 0.9912 \\
CF10 & 0.994 & 0.9916 & 0.979 & 0.981 \\
\hline
\end{tabular}

The broadening of peak and very small peak are observed suggested the presence of drug in a more soluble amorphous state. This was due to inhibition of its crystallization and solubilization in proniosomes.

\section{In vitro release study}

The cumulative amount of drug permeated for each formulation was shown in Figure 5. The result indicated that formulation CF8 was shown higher drug release $57.04 \%$ up to $12 \mathrm{hr}$. The proniosome formulation CF2, CF3, CF5, CF6 and CF8 shows higher drug release up to $12 \mathrm{hr}$. The order of decreasing percentage of drug release was CF8 > CF6 > CF5 $>\mathrm{CF} 3>\mathrm{CF} 2>\mathrm{CF} 10>\mathrm{CF} 9>\mathrm{CF} 7>\mathrm{CF} 1>\mathrm{CF} 4$.

The encapsulation efficiency of formulations batches CF1 to CF10 were shown in Table 2.

\section{Drug release Kinetics}

Calculated regression coefficient $\left(R^{2}\right)$ of formulations for different kinetics model were shown in Table 3. $R^{2}$ values of zero order graphs were found to be higher for formulation CF5, CF8 and CF10 than first order graphs.

To know the further drug release the drug release data was fitted into Korsmeyer Peppa's model and from the value of release exponent ' $n$ ' concluded the drug release. All the formulations shows release exponent ' $n$ ' in between 0.5 to 0.89 . This showed that drug released from all the formulations followed non-Fickian diffusion.

\section{Surface Morphology}

Proniosomes converted into niosomes after hydration and the surface morphology was performed using Scanning Electron Microscopy. SEM photograph Figure 6 showed that niosomes formed were nearly spherical, multilamellar and homogeneous.

\section{Evaluation of carbopol topical proniosomal gel:}

All the five formulations were evaluated for $\mathrm{PH}$, viscosity, Drug content, spreadability, extrudability results were shown in Table 4.

These selected formulations $\mathrm{C} 1 \mathrm{CF} 2, \mathrm{C} 2 \mathrm{CF} 3, \mathrm{C} 3 \mathrm{CF} 5, \mathrm{C} 4 \mathrm{CF} 6$ and C5CF8 developed into carbopol gel. Zero order plot for carbopol gel formulations were presented in Figure 7. Calculated regression coefficient of carbopol gel formulations for different kinetic models were presented in Table 5. Regression coefficient $R^{2}$ value of zero order plot were higher for formulations $\mathrm{C} 1 \mathrm{CF} 2, \mathrm{C} 2 \mathrm{CF} 3, \mathrm{C} 3 \mathrm{CF} 5, \mathrm{C} 4 \mathrm{CF} 6$ and $\mathrm{C} 5 \mathrm{CF} 8$ which indicate that the release rate of drug from the formulation was independent of its concentration and hence follows zero order 
Table 4: PH, Viscosity, Drug Content, Spreadability and Extrudability.

\begin{tabular}{cccccc}
\hline $\begin{array}{c}\text { Formulation } \\
\text { code }\end{array}$ & $\mathrm{PH}^{*}$ & Viscosity* & $\begin{array}{l}\text { Drug } \\
\text { Content* }\end{array}$ & $\begin{array}{l}\text { Spreadability* } \\
\mathrm{gm} / \mathrm{cm}^{2} / \mathrm{Sec} .\end{array}$ & Extrudability* \\
\hline C1CF2 & $6.82 \pm 10$ & $1109 \pm 1.15$ & 93.10 & $11.22 \pm 0.13$ & $82 \pm 0.43$ \\
C2CF3 & $6.76 \pm 05$ & $1078 \pm 1.23$ & 94 & $12.09 \pm 0.10$ & $82 \pm 0.26$ \\
C3CF5 & $7.10 \pm 09$ & $1146 \pm 1.25$ & 93.20 & $12.30 \pm 0.05$ & $83 \pm 0.30$ \\
C4CF6 & $6.24 \pm 13$ & $1257 \pm 2.10$ & 95.24 & $11.20 \pm 0.12$ & $84 \pm 0.24$ \\
C5CF8 & $6.09 \pm 14$ & $1289 \pm 1.07$ & 96.12 & $13.05 \pm 0.14$ & $86 \pm 0.09$ \\
\hline
\end{tabular}

${ }^{*}$ All values represent mean \pm standard deviations $(\mathrm{SD}), n=3$

Table 5: Release Kinetics of Formulations in ex vivo Drug Release, Flux (Jss) and Permeability Coefficient (Kp).

\begin{tabular}{ccccccc}
\hline Formulation & \multicolumn{7}{c}{ Correlation Coefficient of model fitting $\left(R^{2}\right)$} & $\begin{array}{l}\text { Flux } \\
\left(\mu \mathrm{g} / \mathrm{cm}^{2} / \mathrm{hr}^{*}{ }^{*}\right)\end{array}$ & $\begin{array}{c}\text { Permeability } \\
\text { Coefficient (Kp) } \\
\mathrm{cm}^{2} / \mathrm{hr}^{*}\end{array}$ \\
\hline & Zero order & First order & Higuchi & Peppa's & \\
\hline C1CF2 & 0.9797 & 0.9888 & 0.984 & 0.9913 & 4.31 & 0.215 \\
C2CF3 & 0.993 & 0.9904 & 0.979 & 0.9842 & 4.53 & 0.226 \\
C3CF5 & 0.9924 & 0.9778 & 0.9667 & 0.993 & 4.75 & 0.237 \\
C4CF6 & 0.9929 & 0.9923 & 0.979 & 0.9899 & 4.85 & 0.242 \\
C5CF8 & 0.9949 & 0.9902 & 0.975 & 0.9855 & 5.24 & 0.262 \\
\hline
\end{tabular}

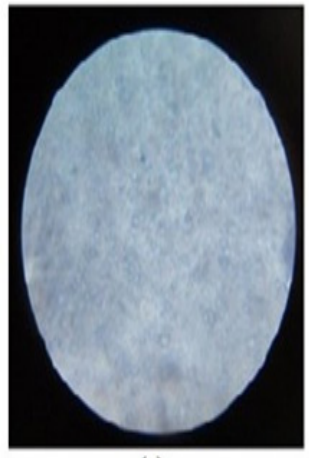

(a)

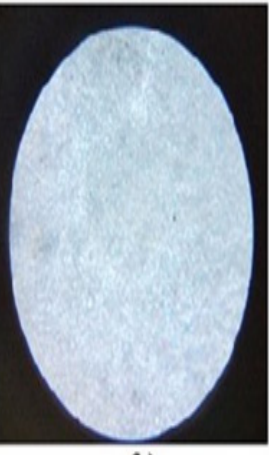

(b)

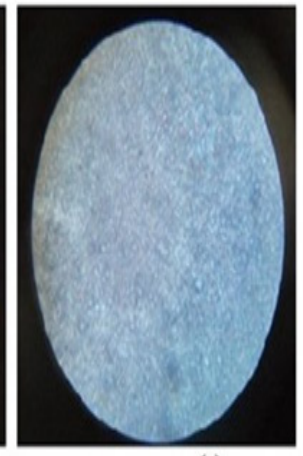

(c)
Figure 4: Optical microscopic examination of CF5 (a), CF6 (b) and CF8 (c)

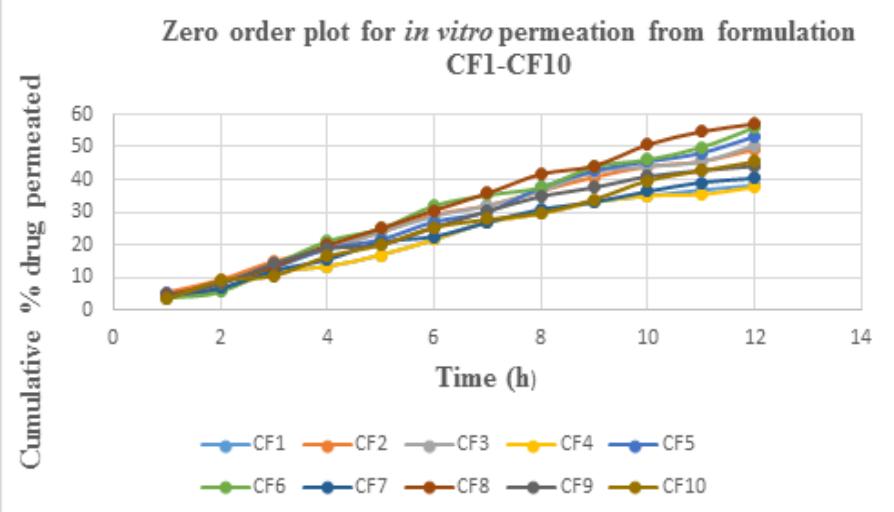

Figure 5: Cumulative percent drug permeation of proniosomal gel of Ciclopirox from CF1 to CF10. release kinetics. Flux value and permeability coefficient of all carbopol gel formulation were shown in Table 5. Among all the formulations, C5CF8 showed higher $R^{2}$ value 0.9949 , higher drug permeation $(P<0.05) 59.39$ $\pm 0.10 \%$ in $12 \mathrm{hr}$. with a flux value of $5.24 \mu \mathrm{g} / \mathrm{cm}^{2} / \mathrm{hr}$. and permeability coefficient of $0.262 \mathrm{~cm}^{2} / \mathrm{hrs}$. C5CF8 had diffusion exponent ' $n$ ' value 0.69 confirm non Fickian diffusion.

\section{Comparative study of Carbopol proniosomal gel with} marketed preparation

The cumulative percentage of drug release was found to be $88.55 \pm$ $0.12 \%$ for marketed preparation and $59.39 \pm 0.10 \%$ for carbopol gel formulation (C5CF8) at the end of $12 \mathrm{hr}$ were shown in Figure 7.

\section{Stability studies}

Optimized formulation C5CF8 was kept in glass vial for 3 months and observed at definitive intervals visually and under optical microscope for change in consistency, aggregation and appearance of drug crystals.

Result of stability study indicated that there was slight change in particle size and \% EE was reduced presented in Table 6.

\section{In vitro antifungal study}

It was detected that the marketed preparation had $7.5 \mathrm{~mm}$ zone of inhibition while formulation C5CF8 in two concentration that is sample $\mathrm{C} 1$ and sample $\mathrm{C}$ had $8.5 \mathrm{~mm}$ and $10 \mathrm{~mm}$ of zone of inhibition respectively which is greater than marketed preparation. Results are presented in Figure 2.

\section{DISCUSSION}

Among the span combination batches, batch containing combination of span 40 and 60 have higher encapsulation efficiency due to the longer saturated alkyl chain compared to that of span 20 and 80 . The entrapment efficiency depends upon surfactant used, their alkyl chain length, phase 
Table 6: Stability Data of Optimized Carbopol Gel Formulation C5CF8.

\begin{tabular}{ccccc} 
Time & \multicolumn{2}{c}{$\begin{array}{c}\text { Refrigerated Temperature }(4 \\
\left. \pm 2{ }^{\circ} \mathrm{C}\right)\end{array}$} & $\begin{array}{l}\text { Room temperature }(25 \\
\left. \pm 2^{\circ} \mathrm{C}\right)\end{array}$ & \\
\hline (Month) & Vesicle size & $\% \mathrm{EE}$ & Vesicle size & $\% \mathrm{EE}$ \\
0 & $4.25 \pm 0.12$ & 92.60 & $5.10 \pm 0.07$ & 92.20 \\
1 & $5.12 \pm 0.10$ & 92.31 & $6.45 \pm 0.13$ & 90.02 \\
2 & $6.07 \pm 0.12$ & 90.13 & $7.02 \pm 0.12$ & 88.10 \\
3 & $6.56 \pm 0.09$ & 89.30 & $7.45 \pm 0.16$ & 86.45 \\
\hline
\end{tabular}

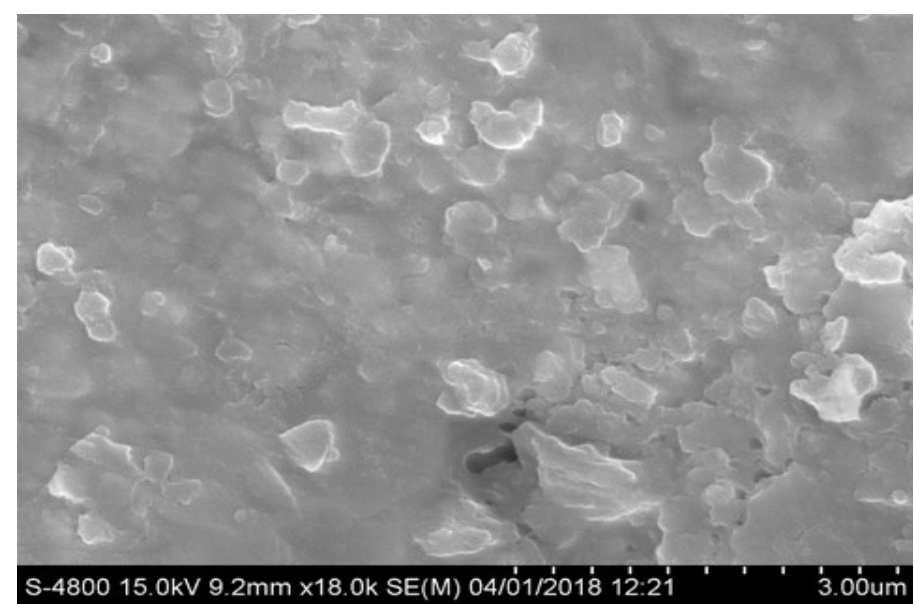

Figure 6: Scanning Electron Microscopic image of proniosomal gel formulation CF8.

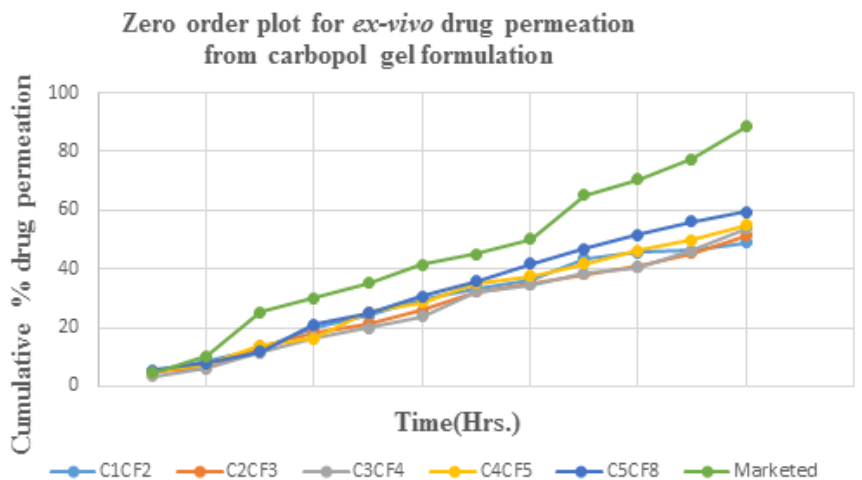

Figure 7: Zero order plot for ex vivo drug permeation from carbopol gel formulation $(P<0.05)$.

transition temperature and HLB values. ${ }^{13}$ Spans have low HLB value and highly lipophilic in nature and formed closed identical bilayer structure in that Ciclopirox gets embedded.

As the length of saturated alkyl chain increases from formulation CF1 to CF10 in span series a significant increase in \%EE was observed. The order of entrapment was Span $60>$ Span $40>$ Span $80>$ Span $20{ }^{12}$ Span 80 and Span 60 had the same polar head, but in Span 80, introduction of double bond give rise to more permeable bilayer and lower entrapment efficiency. ${ }^{12,19}$ Span 60 and span 40 due to its high phase transition temperatures, formed uniform bilayer structure within which lipophilic drug got completely entrapped to give the high entrapment efficiency. Span 20 and Span 80 has lower phase transition temperature and also they are liquid at room temperature and rather low entrapment efficiency. ${ }^{12,20}$ To increase the entrapment efficiency appropriate amount of surfactant concentration will required to form the bilayer structure. A significant increase in niosomes number resulted in the volume of hydrophobic bilayer domain and hence the available space is more for lodging of hydrophobic drug Ciclopirox was increased with increased entrapment efficiency. ${ }^{12,21}$ Cholestrol gets intercalated between bilayers of non-ionic surfactants to form less leaky and rigid bilayers. All the formulation contain appropriate amount $(200 \mathrm{mg})$ of cholestrol so all formulation shows good entrapment efficiency with less difference. Higher cholestrol concentration can strive with the drug for the space inside the bilayers, therefore rejecting the drug and give rise to disruption in the ordered bilayer structure. ${ }^{12}$ Lecithin addition increases the entrapment efficiency of proniosome formulations, by means of increasing the rigidity of bilayer structure, which was credited to the soya lecithin which have high phase transition temperature. ${ }^{12}$ Proniosomal gel formulation CF1,CF4,CF7 which formulated using span 20 and 80 either alone or in combination showed less drug release and entrapment efficiency as compared to formulation CF9 and CF10 which contain span 40 and 60 in combination with Span 80. The CF2 and CF3 formulated with single non-ionic surfactant Span 40 and 60 respectively had more drug release and entrapment efficiency when they were compared with batch CF9 and CF10. This was due to Span 20 and Span 80 were liquid at room temperature and had low phase transition temperature presented comparatively low entrapment efficiency. Span 40 and 60 had high phase transition temperature and longer alkyl chain length.

Among the proniosomal gel formulation the batch CF8 (40:60) showed higher drug permeation up to $12 \mathrm{hrs}$. This might be due to the synergistic emulsification result of the surfactant after the hydration of the proniosomes occurred by the dissolution medium and due to loss of lipid bilayers there was formation of elution canals within the gel structure. The same results have also been observed by Singla $S$ et al. $2012 .{ }^{15}$ Alsarra et al. (2005) has already reported that increasing amount of cholestrol lead to unbroken lipid bilayer which act as a barrier for drug permeation and improved fluidity of the lipid bilayer membrane and reduced permeability leads to decreased its leakage hence drug elution from vesicles get lowered. ${ }^{14}$ In the present study fixed ratio of cholestrol was used $(200 \mathrm{mg})$ which results in formation of rigid bilayer acts as barrier for drug permeation and improved fluidity of the lipid bilayer membrane and reduced permeability leads to decreased its leakage hence drug elution from vesicles get lowered. As the release rate is dependent on alkyl chain length saturation or cholesterol content. Addition of lecithin at optimum concentration have played an important role in drug permeation. ${ }^{14}$ Mixing of two surfactant results in the formation of new type of mixed micelle and the synergistic penetration enhancement effect are concentration dependent which occurs when equal fractions of the surfactant are present in mixture..$^{22}$ Results of present study proved that developed carbopol topical gel had potential to act as controlled release drug carrier which sustain the drug release for number of hours and exhibit good antifungal activity. The proniosomal topical gel might be fruitful substitute for efficient delivery of drug across the skin.

\section{CONCLUSION}

Topical proniosomal gel was formulated and evaluated for antifungal therapy. The co-acervation phase separation method was used to prepared topical proniosomal gel by using different grades of non-ionic surfactant, carbopol, lecithin, and cholestrol was utilized in this study which prolong the release of drug and to improve poor skin penetration and residence of the topical antifungal drugs. Sustained and prolonged release makes the delivery system more reliable and more acceptable to the patients and increases patient compliance. Developed carbopol gel 
had potential to act as controlled release drug carrier which prolonged the drug release for number of hours. Overall, these findings indicate that topical proniosomal gel will be encouraging drug delivery method for Ciclopirox

\section{ACKNOWLEDGEMENT}

I would like to express my sincere gratitude to the Principal Dr. V. R. Patil and guide Dr. R.Y. Chaudhari of TVES's Hon. Loksevak Madhukarrao Chaudhari, College of Pharmacy, Faizpur, Jalgaon, for their generous help and co-ordination during project work.

\section{CONFLICT OF INTEREST}

The author declares no conflict of interest.

\section{ABBREVIATIONS}

HLB: Hydrophilic lipophilic balance; EE: Entrapment Efficiency; SC: Stratum Corneum; PBS: Phosphate buffer.

\section{REFERENCES}

1. Shirsand SB, Keshavshetti GG. Formulation and characterization of drug loaded niosomes for antifungal activity. J Adv Nov Drug Deliv. 2016;1(1):12-7.

2. Gupta AK, Skinner AR. Ciclopirox for the treatment of superficial fungal infections: A review. Int J Dermatology. 2003;42(Suppl 1):3-9.

3. Alli MS, Srilakshmi CH, Ganesan G. Proniosome Gel: An Effective Nove Therapeutic Topical Delivery System. Int J Pharm Tech Res. 2013;5(4):1754-64.

4. Radha GV, Rani TS, Sarvani B. A review on proniosomal drug delivery system for targeted drug action. J Basic Clin Pharm. 2013;4(2):42-8.

5. Indira U, Uma SMS. Proniosomes as a Drug Carrier: A Review. Int J Pharm Sci Res. 2012;3(12):4617-25

6. Maryam KM, Kifayat US, Fakhar UDD, Shefaat US, Rehman AU, Dilawar N, et al. Proniosomes derived niosomes: Recent advancements in drug delivery and targeting, Drug Delivery. 2017;24(2):56-69.

7. Shaikh KS, Chellampillai B, Pawar AP. Studies on nonionic surfactant bilayer vesicles of Ciclopirox Olamine. Drug Dev and Industrial Pharm. 2010;36(8):94653.
8. Pinnika A, Devi AS, Divya P. Formulation and Evaluation of Candesartan Cilexetil Transdermal Proniosomal Gel. J Drug Delivery and Therapeutics. 2014;4(2):90-8.

9. Vora B, Khopade AJ, Jain NK. Proniosome based transdermal delivery of levonorgestrel for effective contraception. J Control Release. 1998;54(2):14965.

10. Gadekar V, Bhowmick M, Pandey G, Joshi A, Dubey B. Formulation And Evaluation Of Naproxen Proniosomal Gel for the Treatment of Inflammatory and Degenerative Disorders of the Musculoskeletal System. J Drug Delivery and Therapeutics. 2013;3(6):36-41.

11. Shirsand SB, Para MS, Nagendrakumar D, Kanani KM, Keerthy D. Formulation and Evaluation of Ketoconazole niosomal gel drug delivery system. Int J Pharm Investig. 2012;2(4):201-7.

12. Sambhakara S, Paliwala S, Sharmaa S, Singh B. Formulation of Risperidone loaded proniosomes for effective transdermal delivery: An in vitro and in vivo study. Bulletin of Faculty of Pharmacy, Cairo University. 2017;55(2);239-47.

13. Mulani $\mathrm{H}$, Bhise KS. ObD Approach in the Formulation and Evaluation of Miconazole Nitrate Loaded Ethosomal Cream-o-gel. Ind Res J Pharm and Sci. 2017;8:001-37.

14. Alsarra IA, Bosela AA, Ahmed SM, Mahrous GM. Proniosomes as a drug carrier for transdermal delivery of ketorolac. Eur J Pharm Biopharm. 2005;59(3):48590.

15. Singla S, Harikumar SL, Aggarwal G. Proniosomes for effective topical delivery of Clotrimazole development characterization and performance evaluation. Asian J Pharm Sci. 2012;7(4):259-70.

16. Soujanya C, Ravi PP. Development and in vivo Evaluation of Lovastatin Loaded Transdermal Proniosomal Gel by Design of Experiment. Int J Pharm Sci Drug Res. 2018;10(4):252-25.

17. Basha BN, Prakasam K, Goli D. Formulation and evaluation of Gel containing Fluconazole-Antifungal Agent. Int J Drug Dev and Res. 2011;3(4):109-28.

18. Kokare C. Pharmaceutical Microbiology Experiments and Techniques. Career Publications. 2010;159-60.

19. Hao Y, Zhao F, Li N, Yang, K. Li, Studies on a high encapsulation of colchicine by niosome system. Int J Pharm. 2001:244(1-2):73-80.

20. Aboelwafa AA, El-Setouhy DA, Elmeshad AN. Comparative study on the effects of some polyoxyethylene alkyl ether and sorbitan fatty acid ester surfactants on the performance of transdermal Carvidilol proniosomal gel using experimental design. AAPS Pharm Sci Tech. 2010;11(4):1591-602.

21. Alsarra IA. Evaluation of proniosomes as an alternative strategy to optimize piroxicam transdermal delivery. J Microencapsul. 2008;26(3):272-8.

22. Azarbayjani AF, Sui $Y$, Tan EH, et al. Transdermal delivery of haloperidol by proniosomal formulation with non-ionic surfactants. Bio Pharm Bull. 2009;32(8):1453-8.

Article History: Submission Date : 22-11-2020; Revised Date : 08-12-2020; Acceptance Date : 01-01-2021

Cite this article: Mahajan SS, Chaudhari RY, Patil VR, Mahajan SS. Formulation and Evaluation of Topical Proniosomal Gel of Ciclopirox for Antifungal Therapy. Int. J. Pharm. Investigation. 2021;11(1):56-62. 